\title{
Chronic Oral Administration of the Arginase Inhibitor 2(S)- amino-6-boronohexanoic Acid (ABH) Improves Erectile Function in Aged Rats
}

\author{
Robert Segal $^{\star}$, Johanna L. Hannan ${ }^{\star}$, Xiaopu Liu*, Omer Kutlu*, Arthur L. Burnett ${ }^{\star}$, Hunter C. \\ Champion $^{\dagger}$, Jae Hyung Kim ${ }^{\ddagger}$, Jochen Steppan ${ }^{\ddagger}$, Dan E. Berkowitz ${ }^{\ddagger} \S$, and Trinity J. \\ Bivalacqua* $^{*}$
}

*Department of Urology, The James Buchanan Brady Urological Institute, Johns Hopkins Medical Institutions, Baltimore, Maryland tDepartment of Medicine and the Vascular Medicine Institute, University of Pittsburgh, Pittsburgh, Pennsylvania \#Department of Anesthesiology and Critical Care Medicine, Johns Hopkins Medical Institutions, Baltimore, Maryland §Department of Biomedical Engineering, Johns Hopkins Medical Institutions, Baltimore, Maryland

\begin{abstract}
Arginase expression and activity have been noted to be heightened in conditions associated with erectile dysfunction, including aging. Previously, arginase inhibition by chronic administration of the arginase inhibitor 2-(S)-amino-6-boronohexanoic acid (ABH) has been shown to improve endothelial dysfunction in aged rats. The objective of this study was to assess whether chronic oral $\mathrm{ABH}$ administration affects cavernosal erectile function. Rats were divided into 4 groups: young control, young treated with arginase inhibitor, aged control, and aged treated with arginase inhibitor. Arginase activity was measured and presented as a proportion of young untreated rats. In vivo erectile responses to cavernous nerve stimulation were measured in all cohorts. The cavernous nerve was stimulated with a graded electrical stimulus, and the intracavernosal/ mean arterial pressure ratios and total intracavernosal pressure were recorded. Arginase activity was elevated in the aged rats compared with young controls; however, arginase activity was significantly decreased in aged rats treated with $\mathrm{ABH}$. With the addition of $\mathrm{ABH}$, erectile responses improved in the aged rats $(P<.05)$. Oral inhibition of arginase with $\mathrm{ABH}$ results in improved erectile function in aged rats, resulting in erectile hemodynamics similar to young rats. This represents the first documentation of systemic arginase inhibition positively affecting corporal cavernosal function.
\end{abstract}

\section{Keywords}

Erectile dysfunction; nitric oxide; penile erection; aging

Copyright $(\odot)$ American Society of Andrology

Correspondence to: Dr Robert Segal, Department of Urology, The Johns Hopkins Hospital, 600 N Wolfe St, Marburg 405, Baltimore, MD 21287-2411 (rsegal3@jhmi.edu). 
Erectile dysfunction (ED) is a serious health concern for men that has major quality-of-life implications, particularly among aging men (Feldman et al, 1994; Albersen et al, 2012). There are multiple risk factors for ED, including arteriosclerosis, diabetes mellitus, hypertension, hypogonadism, depression, and advanced age (Feldman et al, 1994; Ahn et al, 2007; Teles et al, 2008). Aging itself has been shown to be associated with endothelial dysfunction, which in the absence of other risk factors contributes to declining erectile function (Musicki et al, 2005; Figueiredo et al, 2011).

Penile erection is mediated by the production of nitric oxide (NO), which is synthesized by NO synthase (NOS) from $\mathrm{L}$-arginine (Burnett et al, 1992). Arginase is an enzyme of the urea cycle whose function is the catalysis of $\mathrm{L}_{\mathrm{L}}$-arginine to form $\mathrm{L}_{\mathrm{L}}$-ornithine and urea. There are two isoforms: arginase I, found predominantly in the liver, and arginase II, a mitochondrial enzyme (Masuda, 2008), although both have been localized to the vascular endothelium, smooth muscle in general as well as human corpus cavernosum (Cox et al, 1999; Wei et al, 2000; Bivalacqua et al, 2001b; Zhang et al, 2001; Berkowitz et al, 2003). Given that arginine is the common substrate for both NOS and arginase, arginase activity can inhibit endothelium-derived NO production by depleting the available substrate needed for its biosynthesis (Berkowitz et al, 2003; White et al, 2006). Penile arginase expression and activity have been shown to be elevated in a variety of conditions known to be associated with ED, namely, smoking (Imamura et al, 2007), diabetes mellitus (Bivalacaqua et al, 2001b; Jelodar et al, 2007), Peyronie disease (Bivalacqua et al, 2001a), hypertension (Toque et al, 2010), and aging (Bivalacqua et al, 2007; Numao et al, 2007). Furthermore, reduction of arginase activity in the penis via gene knockout or arginase inhibition in vitro and in vivo results in improvement in endothelial cell function and restored erectile responses (Bivalacqua et al, 2007; Kim et al, 2009; Toque et al, 2011).

Arginase inhibitors have been developed for the treatment of vascular disorders related to impaired endothelial cell function. 2(S)-amino-6-boronohexanoic acid (ABH) is a highly selective competitive inhibitor of arginase (Baggio et al, 1999), and has proven useful for assessing the role of arginase in various organ systems. In addition to its expression in the corpus cavernosum and influence on erectile function, arginase has also been localized to the pancreas (Stickings et al, 2002), spinal cord (Xu et al, 2003), and lungs (Maarsingh et al, 2011). Inhibition of arginase using the selective inhibitor $\mathrm{ABH}$ has proven to be therapeutic, at least experimentally, in animal models of diabetes mellitus type 1, autoimmune encephalitis, and chronic asthma, respectively, as well as age-related vascular stiffness (Stickings et al, 2002; Xu et al, 2003; Kim et al, 2009; Maarsingh et al, 2011). Therefore, the aims of our study were to determine whether systemic administration of $\mathrm{ABH}$ could restore impaired erectile function in aging rats. Second, we sought to determine whether $\mathrm{ABH}$ therapy could significantly reduce arginase activity in the penile vasculature of aged rats.

\section{Materials and Methods}

\section{Animals}

Old (age 22-24 months) and young (age 3 months) male Fischer 344 rats were used in the present study. The Fischer 344 strain has been widely used in aging studies and has been shown by Miller et al (2007) to have a progressive rather than an abrupt development of 
age-related pathophysiology. All of the surgical procedures and experimental protocols were approved by the institutional animal care and use committee.

\section{Chronic Arginase Inhibition}

Rats were equally divided into 4 groups: young control, young rats treated with arginase inhibitor, old (aged) control, and old (aged) treated with arginase inhibitor ABH (Baggio et al, 1997; Di Costanzo et al, 2005; Kim et al, 2009). Each rat consumed $400 \mu \mathrm{g}$ of ABH in water daily for 25 days. Control groups were given normal tap water. There was no obvious difference in the consumption of water between the treatment and control groups. $\mathrm{ABH}\left(K_{\mathrm{d}}\right.$ $=5 \mathrm{nM}$ against human Arg 1 ; Di Costanzo et al, 2005) was synthesized as previously reported (Baggio et al, 1997; Xu et al, 2003).

\section{Measurement of Erectile Response}

To measure the erectile response in vivo, after the 25 days of either $\mathrm{ABH}$ treatment or control diet administration, the rats were anesthetized with pentobarbital $(30 \mathrm{mg} / \mathrm{kg}$ intraperitoneally) and placed on a thermoregulated surgical table. Prior to performing in vivo experiments, there was a 24- to 48-hour washout period of ABH. A carotid artery was cannulated (PE-50 tubing) to measure the mean systemic arterial pressure (MAP). As previously described, a 25 -Gauge needle filled with $250 \mathrm{U} / \mathrm{mL}$ heparin and connected to PE-50 tubing was inserted into the right crura and connected to a pressure transducer to permit continuous measurement of intracavernosal pressure (ICP; Bivalacqua et al, 2003, 2004). The right major pelvic ganglion and cavernosal nerve (CN) were identified posterolaterally to the prostate on one side, and an electrical stimulator with a stainless-steel bipolar hook was placed around the CN. MAP and ICP were measured with a pressure transducer connected to a data acquisition system (Biopac Systems, Santa Barbara, California). The $\mathrm{CN}$ was stimulated with a square-pulse stimulator (Grass Instruments, Quincy, Massachusetts) at a frequency of $15 \mathrm{~Hz}$ and pulse width of 30 seconds. The application of $2,4,6$, and $8 \mathrm{~V}$ was used in the present protocol to achieve a significant and consistent erectile response. The duration of stimulation was 1 minute, with rest periods of 2 to 3 minutes between subsequent stimulations. Total erectile response or total ICP was determined by the area under the erectile curve (AUC; $\mathrm{mm} \mathrm{Hg} * \mathrm{~s}$ ) from the beginning of $\mathrm{CN}$ stimulation until the ICP returned to baseline or prestimulation pressures. During stimulation, the peak ICP was registered from the level of the basal ICP. The ratio between the maximum ICP and MAP obtained at the peak of the erectile response was calculated to normalize for variations in systemic blood pressure. The Johns Hopkins Hospital Animal Care and Use Committee approved all procedures used in the present study.

\section{Arginase Activity Assay}

Following ICP/MAP measurements, penes were excised and immediately frozen. Arginase activity was measured by determining levels of urea production by colorimetric analysis (QuantiChrom Arginase Assay Kit, BioAssay Systems, Hayward, California) as previously described (White et al, 2006; Kim et al, 2009). Penes were homogenized in extraction buffer (50 mM potassium phosphate buffer, $\mathrm{pH}$ 7.0; $1 \mathrm{mM}$ EDTA; $1 \mathrm{mM}$ ethylene glycol tetraacetic acid; $0.2 \mathrm{mM}$ phenylmethanesulfonylfluoride; $1 \mu \mathrm{g} / \mathrm{mL}$ pepstatin; $0.5 \mu \mathrm{g} / \mathrm{mL}$ 
leupeptin; $10 \mathrm{mM} \mathrm{NaF} ; 2 \mathrm{mM} \mathrm{Na} 3 \mathrm{VO}_{4}$; and $10 \mathrm{mM} \beta$-mercaptoethanol), and centrifuged for 30 minutes at $14000 \times g$ at $4^{\circ} \mathrm{C}$. Protein concentration was determined by the BCA kit (Pierce, Rockford, Illinois), and $40 \mu \mathrm{g}$ of penile lysates from each sample was used for the measurement of arginase activity. The hydrolysis reaction of $\mathrm{L}$-arginine by arginase was performed by incubating the mixture containing activated arginase and was stopped by adding acid solution. For calorimetric determination of urea, $\boldsymbol{a}$-isonitrosopropiophenone was added, and the mixture was heated at $100^{\circ} \mathrm{C}$ for 45 minutes. After placing the sample in the dark for 10 minutes at room temperature, the urea concentration was determined spectrophotometrically by the absorbance at $550 \mathrm{~nm}$. Arginase activity was expressed as a percentage of the Young activity to account for differences between the activity assays performed.

\section{Statistics}

Data were expressed as mean \pm SEM. Differences between multiple groups were compared by analysis of variance (ANOVA) followed by Newman-Keuls multiple comparisons test. Two-group analysis was performed by $t$ test (paired or unpaired as appropriate). Serial studies were tested by repeated measures ANOVA. $P$ value of less than .05 was used as criteria for statistical significance.

\section{Results}

\section{Chronic Arginase Inhibition Restores Erectile Function in Aged Rats}

We have previously shown that aging impairs erectile function in rodent models of ED (Bivalacqua et al, 2007). Therefore, the effect of systemic administration of the arginase inhibitor $\mathrm{ABH}$ on in vivo erectile responses to CNS was evaluated in young and aged rats. These data are summarized in Figures 1 and 2. Figure 1 represents maximum ICP, maximum ICP/MAP, and total ICP (AUC) for a 4-V stimulation of the $\mathrm{CN}$ with representative ICP tracings for each group. The maximum ICP, ICP/MAP, and total ICP were significantly reduced $(P<.05)$ in aged rats compared with erectile responses of young rats at $4 \mathrm{~V}$ (Figure 1). With $\mathrm{ABH}$ administration, no change was seen in the erectile response of young rats (Figure 1). However, in aged rats treated with ABH, a significant $(P<.05)$ increase in the maximum penile hemodynamic parameters was found at $4 \mathrm{~V}$, approaching that seen in young rats for maximum ICP and ICP/MAP (Figure 2b). For the total ICP response at $4 \mathrm{~V}$, aged rats treated with $\mathrm{ABH}$ had total erectile responses that were significantly greater than aged and young rats treated with or without ABH (Figure 1b).

To evaluate the effect of $\mathrm{ABH}$ inhibition on young and aged rat penile erectile hemodynamics, in vivo erectile response to CNS at increasing voltage settings was studied. These data are summarized in Figure 2. There was a significant $(P<.05)$ decline in erectile function in aged rats compared with young rats (Figure 2). The ratio of ICP/MAP and total ICP (AUC; $\mathrm{mm} \mathrm{Hg}^{*}$ s) after CNS in aged rats were significantly lower $(P<.05)$ than that of young animals at all levels of stimulation (Figure 2). In aged rats treated with $\mathrm{ABH}$, the ICP/MAP was significantly increased $(P<.05)$ at all voltage settings to values similar to those for young rats (Figure 2). The most dramatic change in erectile hemodynamic indices was evident in the total ICP of rats treated with $\mathrm{ABH}$. There was a significant increase in 
total ICP in aged rats treated with $\mathrm{ABH}$ to values greater than those found in young rats treated with or without $\mathrm{ABH}$ (Figure 2). We saw no change in erectile function in young rats treated with $\mathrm{ABH}$ (Figure 2). These data demonstrate that severe ED occurring in aged rats is reversed with the selective arginase inhibitor $\mathrm{ABH}$.

There were no differences in baseline ICP or MAP in the groups, with the exception of the young rats treated with $\mathrm{ABH}$. This group showed a small but statistically significant elevation in MAP $(P<.05$; Figure 3$)$.

\section{Arginase Activity}

Total arginase activity was measured in young and aged penes with and without treatment with $\mathrm{ABH}$, and these data are summarized in Figure 4. Total penile arginase activity levels were significantly higher $(P<.05)$ in the aged rat penes compared with young activity levels (Figure 4). The arginase inhibitor ABH significantly decreased $(P<.05)$ the total arginase activity in aged rat penes to values similar to those of young rats (Figure 4).

\section{Discussion}

The present study demonstrates that chronic systemic arginase inhibition with $\mathrm{ABH}$ markedly improves erectile hemodynamics in aged rats. Treatment with ABH reduced total arginase activity in the aged penis and resulted in significant improvements in erectile responses in aged rats. The fact that there is no significant difference in ICP/MAP ratios in young rats treated with the selective arginase inhibitor further supports the notion that corporal arginase activity is significantly increased in aging and contributes to ED in aged rats in the absence of other known risk factors.

Vascular disease remains a significant complication of aging, and it is central to the development of a number of age-related pathologies. Aging results in damage to the small blood vessels (microvascular disease), neuropathy, and vascular stiffness, which are the hallmark features of peripheral vascular disease. There are a number of cellular and molecular changes that occur in the systemic vasculature with aging that cause endothelial dysfunction. L-Arginine is the required substrate for the generation of NO by NOS. It is also metabolized by arginase, which results in the generation of ornithine and urea. Arginase has been localized to the human corpus cavernosum (Cox et al, 1999; Bivalacqua et al, 2001b), and its physiologic role has been postulated to be maintenance of intrinsic corporal smooth muscle tone (Masuda et al, 2004). This mechanism likely occurs as a result of NOS substrate depletion, which decreases the amount of NO generated, with resultant smooth muscle contraction. Up-regulation of arginase has as such been associated with a variety of conditions known to be risk factors for ED (Bivalacaqua et al, 2001a,b; Imamura et al, 2007; Jelodar et al, 2007), and is considered to be a major molecular mechanism that impairs penile endothelial cell function. In particular, aging itself has been linked to heightened arginase expression and activity (Numao et al, 2007), which is localized to the penile endothelium and smooth muscle (Bivalacqua et al, 2007), and aging is known to be associated with ED (Feldman et al, 1994). In the present study we demonstrate an increase in total arginase activity in the penis with associated impaired in vivo erectile function, 
suggesting that an elevation in arginase expression and activity contributes to corporal vascular dysfunction in aging.

Although inhibition of arginase via gene knockout or gene therapy techniques has been shown to improve erectile function (Bivalacqua et al, 2003; Toque et al, 2011) in rats and mice, this has not been demonstrated with an orally administrated arginase inhibitor, a factor that is critical for practical ED pharmacotherapy. Therefore, the purpose of this study was to assess whether arginase inhibition with a potent, selective arginase inhibitor (Baggio et al, 1999) administered via chronic oral supplementation would have an impact on penile vascular hemodynamics in an animal model of aging. We show that aged rats have significantly impaired erectile responses to CNS. In vivo erectile parameters are restored in aged rats treated with the arginase inhibitor $\mathrm{ABH}$ and compare with those of young rats, without a systemic effect on mean arterial blood pressure. We found no change in erectile function in young rats treated with $\mathrm{ABH}$, suggesting that arginase inhibition only influences penile vascular function in the presence of elevated arginase expression and activity.

Several complex mechanisms are thought to contribute to the pathogenesis of age-related penile vascular dysfunction. Natural aging results in significant fibrosis of the corpora cavernosa (Ferrini et al, 2001). One potential mechanism of increased collagen deposition and fibrosis of the penis in aging may be associated with increased arginase signaling in the penis. Increased production of urea and ornithine by arginase leads to vascular hyperplasia and fibrosis (Alef et al, 2011) through increased production of proline synthesis. Thus, the improved erectile responses in rats treated with $\mathrm{ABH}$ may be associated with a reduction in collagen deposition and fibrosis, thus improving corporal vascular resistance and blood flow.

Further study is required to elucidate the exact mechanism by which systemic arginase inhibition results in improved erectile function. Although depletion of NOS substrate is certainly plausible, other mechanisms may have a critical role. Endothelial dysfunction manifested by endothelial NOS (eNOS) uncoupling and higher oxidative stress were shown to be significantly elevated in the aged rat penile vasculature (Bivalacqua et al, 2007; Kim et al, 2009; Johnson et al, 2011). Therefore, arginase inhibition may improve endothelial cell function by reversing eNOS uncoupling and reducing oxidative stress. We have previously shown that in human corporal cavernosal tissue obtained from diabetic patients, inhibition of arginase in vitro improved constitutive NOS activity, supporting the concept that arginase inhibition improves endothelial cell function in the penis (Bivalacqua et al, 2001a). Furthermore, there are multiple other molecular mechanisms that have been ascertained to be responsible for age-related ED in both preclinical and human studies that may be implicated. These include differential phosphorylation of eNOS (Musicki et al, 2005), altered corporal body structure (Bakirciorglu et al, 2001; Costa and Vendeira, 2008), increased endogenous NOS inhibitors (Imamura et al, 2007), corporal cavernosal extracellular matrix production and resultant fibrosis (Castela et al, 2011), and increased smooth muscle contractility as a result of increased RhoA/Rho-kinase activity (Jin et al, 2006). A major limitation to this study is the lack of direct NO measurement in the rats treated with the arginase inhibitor. Therefore, further studies are warranted to delineate the 
compensatory molecular changes, such as improved NO biosynthesis, that occur in the penis and which influence erectile physiology and ultimate functional recovery of penile erections.

In conclusion, this is the first study to demonstrate an in vivo effect on penile vascular function in aged rats treated with the oral arginase inhibitor $\mathrm{ABH}$. The results further support the notion that the arginase pathway may be exploited for the treatment of ED associated with aging.

\section{Acknowledgments}

Supported by a K08 National Institutes of Health Career Development Award (T.J.B.) and a Canadian Institutes of Health Research Fellowship (J.L.H.).

\section{References}

Ahn TY, Park JK, Lee SW, Hong JH, Park NC, Kim JJ, Park K, Park H, Hyun JS. Prevalence and risk factors for erectile dysfunction in Korean men: results of an epidemiological study. J Sex Med. 2007; 4:1269-1276. [PubMed: 17635695]

Albersen M, Orabi H, Lue TF. Evaluation and treatment of erectile dysfunction in the aging male: a mini-review. Gerontology. 2012; 58(1):3-14. [PubMed: 21912081]

Alef MJ, Vallabhaneni R, Carchman E, Morris SM Jr, Shiva S, Wang Y, Kelley EE, Tarpey MM, Gladwin MT, Tzeng E, Zuckerbraun BS. Nitrite-generated NO circumvents dysregulated arginine/NOS signaling to protect against intimal hyperplasia in Sprague-Dawley rats. J Clin Invest. 2011; 121(4):1646-1656. [PubMed: 21436585]

Baggio R, Elbaum D, Kanyo ZF, Carroll PJ, Cavalli RC, Ash DE, Christianson DW. Inhibition of $\mathrm{Mn}^{2+}$ 2-arginase by borate leads to the design of a transition state analogue inhibitor, 2(S)-amino-6boronohexanoic acid. J Am Chem Soc. 1997; 119:8107-8108.

Baggio R, Emig FA, Christianson DW, Ash DE, Chakder S, Rattan S. Biochemical and functional profile of a newly developed potent and isozyme-selective arginase inhibitor. J Phramacol Exp Ther. 1999; 290:1409-1416.

Bakircioglu ME, Sievert KD, Nunes L, Lau A, Lin CS, Lue TF. Decreased trabecular smooth muscle and caveolin-1 expression in the penile tissue of aged rats. J Urol. 2001; 166:734-738. [PubMed: 11458126]

Berkowitz DE, White R, Li D, Minhas KM, Cernetich A, Kim S, Burke S, Shoukas AA, Nyhan D, Champion HC, Hare JM. Arginase reciprocally regulates nitric oxide synthase activity and contributes to endothelial dysfunction in aging blood vessels. Circulation. 2003; 108:2000-2006. [PubMed: 14517171]

Bivalacqua TJ, Burnett AL, Hellstrom WJG, Champion HC. Overexpression of arginase in the aged mouse penis impairs erectile function and decreases eNOS activity: influence of in vivo gene therapy of anti-arginase. Am J Heart Circ Physiol. 2007; 292:H1340-H1351.

Bivalacqua TJ, Champion HC, Leungwattanakij S, Yang DY, Hyun JS, Abdel-Mageed AB, Sikka SC, Kadowitz PJ, Hellstrom WJ. Evaluation of nitric-oxide synthase and arginase in the induction of a Peyronie's-like condition on the rat. J Androl. 2001b; 22:497-506. [PubMed: 11330651]

Bivalacqua TJ, Hellstrom WGJ, Kadowitz PJ, Champion HC. Increased expression of arginase II in human diabetic corpus cavernosum: in diabetic-associated erectile dysfunction. Biochem Biophys Res Commun. 2001a; 283:923-927. [PubMed: 11350073]

Bivalacqua TJ, Usta MF, Champion HC, Adams D, Namara DB, Abdel-Mageed AB, Kadowitz PJ, Hellstrom WJ. Gene transfer of endothelial nitric oxide synthase partially restores nitric oxide synthesis and erectile function in streptozotocin diabetic rats. J Urol. 2003; 169:1911-1917. [PubMed: 12686872]

Bivalacqua TJ, Usta MF, Champion HC, Leungwattanakij S, Dabisch PA, McNamara DB, Kadowitz PJ, Hellstrom WJ. Effect of combination endothelial nitric oxide synthase gene therapy and 
sildenafil on erectile function in diabetic rats. Int J Impot Res. 2004; 16:21-29. [PubMed: 14963467]

Burnett AL, Lowenstein CJ, Bredt DS, Chang TS, Snyder SH. Nitric oxide: a physiologic mediator of penile erection. Science. 1992; 257:401-403. [PubMed: 1378650]

Castela A, Soares R, Rocha F, Vendeira P, Virag R, Costa C. Erectile tissue molecular alterations with aging: differential activation of the p42/44 MAP Kinase pathway. Age (Dordr). 2011; 33:119-130. [PubMed: 20628826]

Costa C, Vendeira P. Does erectile tissue angioarchitecture modify with aging?: an immunohistological and morphometric approach. J Sex Med. 2008; 5:833-840. [PubMed: 18221283]

Cox JD, Kim NN, Traish AM, Christianson DW. Arginase-boronic acid complex highlights a physiological role in erectile function. Nat Struct Biol. 1999; 6:1043-1047. [PubMed: 10542097]

Di Costanzo L, Sabio G, Mora A, Rodriguez PC, Ochoa AC, Centeno F, Christianson DW. Crystal structure of human arginase I at 1.29-A resolution and exploration of inhibition in the immune response. Proc Natl Acad Sci U S A. 2005; 102:13058-13063. [PubMed: 16141327]

Feldman HA, Goldstein I, Hatzichristou DG, Krane RJ, McKinlay JB. Impotence and its medical and psychosocial correlates: results of the Massachusetts Male Aging Study. J Urol. 1994; 151:54-61. [PubMed: 8254833]

Ferrini M, Magee TR, Vernet D, Rajfer J, González-Cadavid NF. Aging-related expression of inducible nitric oxide synthase and markers of tissue damage in the rat penis. Biol Reprod. 2001; 64:974-982. [PubMed: 11207215]

Figueiredo A, Cordeiro AL, Tomada N, Tomada I, Rodrigues A, Gouveia A, Neves D. Real-time PCR study of Ang1, Ang2, Tie-2, VEGF, and KDR expression in human erectile tissue during aging. J Sex Med. 2011; 8:1341-1351. [PubMed: 21091880]

Imamura M, Waseda Y, Marinova GV, Ishibashi T, Obayashi S, Sasaki A, Nagai A, Azuma H. Alterations of NOS, arginase, and DDAH protein expression in rabbit cavernous tissue after administration of cigarette smoke extract. Am J Physiol Regul Integr Comp Physiol. 2007; 293:R2081-R2089. [PubMed: 17881617]

Jelodar G, Razmi N, Gholampour V. Arginase alteration in the reproductive system of alloxan-diabetic dogs. J Reprod Dev. 2007; 53:317-321. [PubMed: 17179654]

Jin L, Liu T, Lagoda GA, Champion HC, Bivalacqua TJ, Burnett AL. Elevated RhoA/Rho-kinase activity in the aged rat penis: mechanism for age-associated erectile dysfunction. FASEB J. 2006; 20:536-538. [PubMed: 16396994]

Johnson JM, Bivalacqua TJ, Lagoda GA, Burnett AL, Musicki B. eNOS-uncoupling in age-related erectile dysfunction. Int J Impot Res. 2011; 23:43-48. [PubMed: 21289638]

Kim JH, Bugaj LJ, Oh YJ, Bivalacqua TJ, Ryoo S, Soucy KG, Santhanam L, Webb A, Camara A, Sikka G, Nyhan D, Shoukas AA, Ilies M, Christianson DW, Champion HC, Berkowitz DE. Arginase inhibition restores NOS coupling and reverses endothelial dysfunction and vascular stiffness in old rats. J Appl Physiol. 2009; 107:1249-1257. [PubMed: 19661445]

Maarsingh H, Dekkers BG, Zuidhof AB, Bos IS, Menzen MH, Klein T, Flik G, Zaagsma J, Meurs H. Increased arginase activity contributes to airway remodelling in chronic allergic asthma. Eur Respir J. 2011; 38(2):318-328. [PubMed: 21310883]

Masuda H. Significance of nitric oxide and its modulation mechanisms by endogenous nitric oxide synthase inhibitors and arginase in the micturition disorders and erectile dysfunction. Int $\mathrm{J}$ Urol. 2008; 16:128-134. [PubMed: 18269446]

Masuda H, Yano M, Sakai Y, Kihara K, Yamauchi Y, Azuma H. Modulation of intrinsic cavernous tone and nitric oxide production by arginase in rabbit corpus cavernosum. J Urol. 2004; 171:490494. [PubMed: 14665961]

Miller SJ, Watson WC, Kerr KA, Labarrere CA, Chen NX, Deeg MA, Unthank JL. Development of progressive aortic vasculopathy in a rat model of aging. Am J Physiol Heart Circ Physiol. 2007; 293:H2634-H2643. [PubMed: 17873024]

Musicki B, Kramer MF, Becker RE, Burnett AL. Age-related changes in phosphorylation of endothelial nitric oxide synthase in the rat penis. J Sex Med. 2005; 2:347-355. [PubMed: 16422866] 
Numao N, Masuda H, Sakai Y, Okada Y, Kihara K, Azuma H. Roles of attenuated neuronal nitricoxide synthase protein expression and accelerated arginase activity in impairing neuro genic relaxation of corpus cavernosum in aged rabbits. BJU Int. 2007; 99:1495-1499. [PubMed: 17428245]

Stickings P, Mistry SK, Boucher JL, Morris SM, Cunningham JM. Arginase expression and modulation of IL-1beta-induced nitric oxide generation in rat and human islets of Langerhans. Nitric Oxide. 2002; 7:289-296. [PubMed: 12446178]

Teles AG, Carreira M, Alarcão V, Sociol D, Aragüés JM, Lopes L, Mascarenhas M, Costa JG. Prevalence, severity, and risk factors for erectile dysfunction in a representative sample of 3,548 Portuguese men aged 40 to 69 years attending primary healthcare centers: results of the Portuguese erectile dysfunction study. J Sex Med. 2008; 5:1317-1324. [PubMed: 18194181]

Toque HA, Romero MJ, Tostes RC, Shatanwi A, Chandra S, Carneiro ZN, Inscho EW, Webb RC, Caldwell RB, Caldwell RW. p38 mitogen-activated protein kinase (MAPK) increases arginase activity and contributes to endothelial dysfunction in copora cavernosa from angiotensin-II-treated mice. J Sex Med. 2010; 7:3857-3867. [PubMed: 20807329]

Toque HA, Tostes RC, Yao L, Xu Z, Webb RC, Caldwell RB, Caldwell RW. Arginase II deletion increases corpora cavernosa relaxation in diabetic mice. J Sex Med. 2011; 8:722-733. [PubMed: 21054801]

Wei LH, Jakobs AT, Morris SM Jr, Ignarro LJ. IL-4 and IL-13 upregulate arginase I expression by cAMP and JAK/STAT6 pathways in vascular smooth muscle cells. Am J Physiol. 2000; 279:C248-C256.

White AR, Ryoo S, Li D, Champion HC, Steppan J, Wang D, Nyhan D, Shoukas AA, Hare JM, Berkowitz DE. Knockdown of arginase I restores NO signaling in the vasculature of old rats. Hypertension. 2006; 47:245-251. [PubMed: 16380531]

Xu L, Hilliard B, Carmody RJ, Tsabary G, Shin H, Christianson DW, Chen YH. Arginase and autoimmune inflammation in the central nervous system. Immunology. 2003; 110:141-148. [PubMed: 12941151]

Zhang C, Hein TW, Wang W, Chang CI, Kuo L. Constitutive expression of arginase in microvascular endothelial cells counteracts nitric oxide-mediated vasodilatory function. FASEB J. 2001; 15:1264-1266. [PubMed: 11344108] 
a

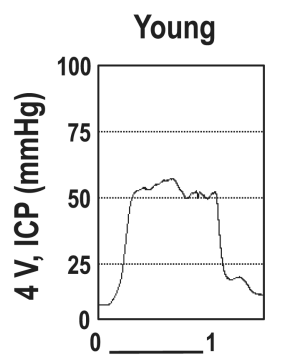

b

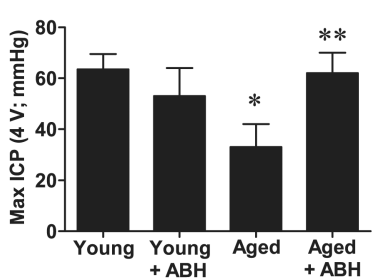

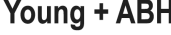

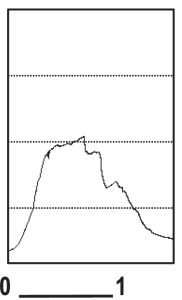

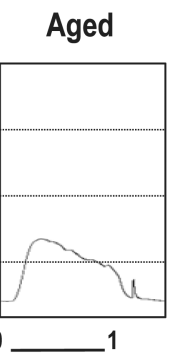

Aged + ABH
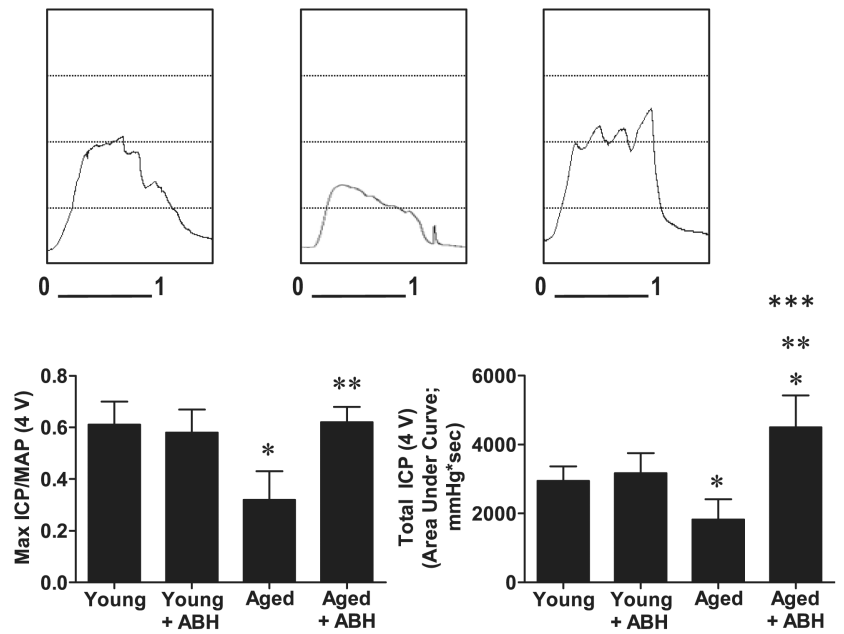

Figure 1.

(a) Representative intracavernosal (ICP) tracing to cavernous nerve stimulation (CNS; 4 V) in young and aged rats with and without treatment with 2-(S)-amino-6-boronohexanoic acid $(\mathrm{ABH})$. (b) Maximum ICP, ICP/mean systemic arterial pressure (ICP/MAP), and total ICP to $\mathrm{CNS}(4 \mathrm{~V})$ in all experimental rat cohorts. $\mathrm{n}$ indicates number of experiments; $*, P<.05$, response significantly different compared with young; $* *, P<.05$, response significantly different compared with aged; $* * *, P<.05$, response significantly different compared with young, young $+\mathrm{ABH}$, and aged. 

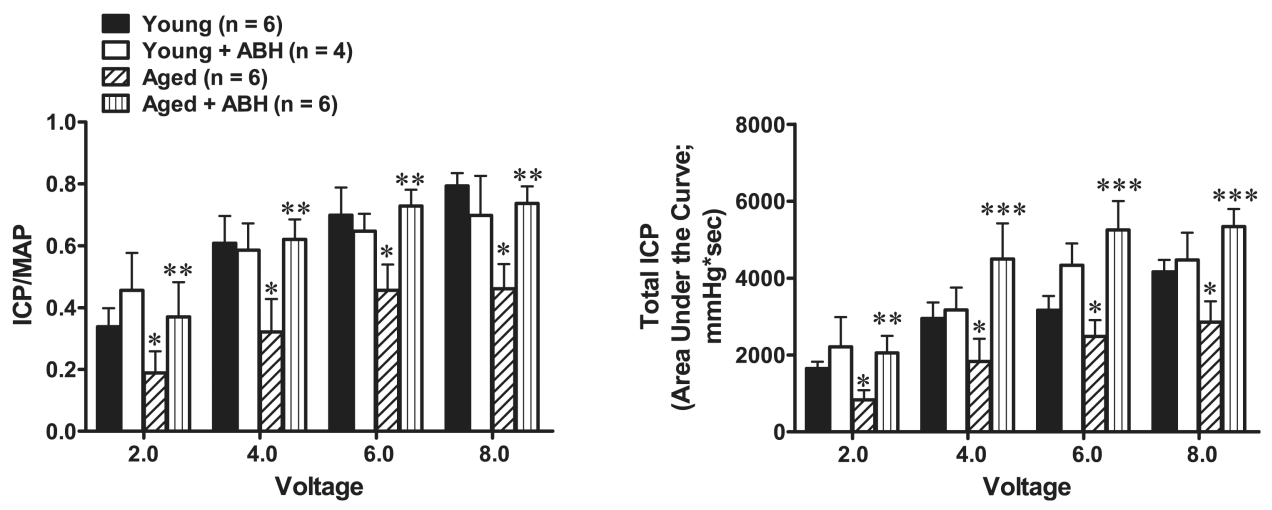

Figure 2.

Bar graph depicting the voltage-dependent erectile response as measured by the intracavernosal pressure/mean systemic arterial pressure (ICP/MAP) ratio, and total ICP (area under the erectile curve) after cavernous nerve stimulation for 1 minute in young and aged rats with and without treatment with 2- $(S)$-amino-6-boronohexanoic acid $(\mathrm{ABH}) . \mathrm{n}$ indicates number of experiments; ${ }^{*}, P<.05$, response significantly different compared with young; $* *, P<.05$, response significantly different compared with aged; $* * *, P<.01$ response significantly different compared with aged. 

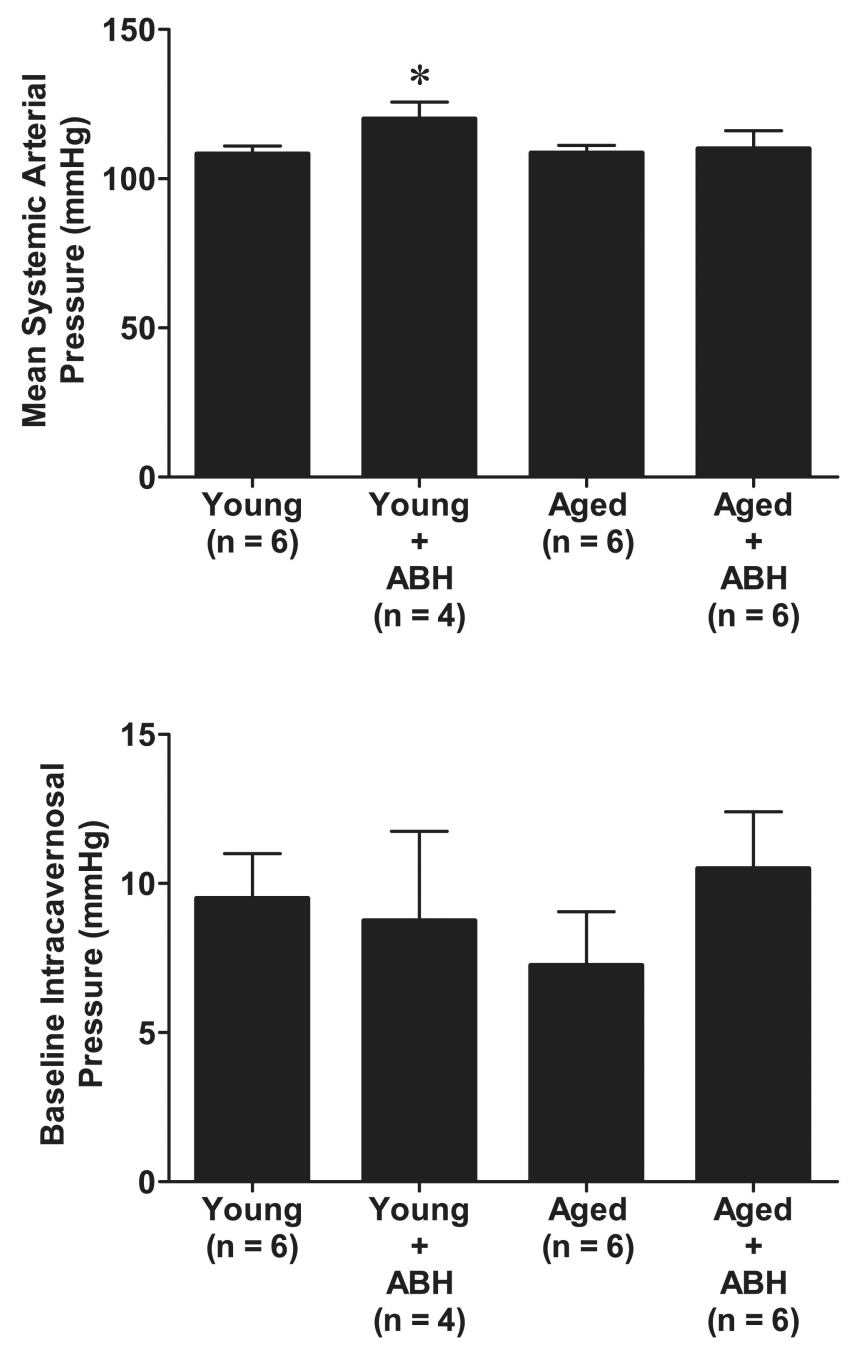

Figure 3.

Mean systemic arterial blood pressure and baseline intracavernosal pressure in young and aged anesthetized rats with and without treatment with the arginase inhibitor 2-(S)-amino-6boronohexanoic acid (ABH). $\mathrm{n}$ indicates number of tissue samples; $* P<.05$ when compared with young. 


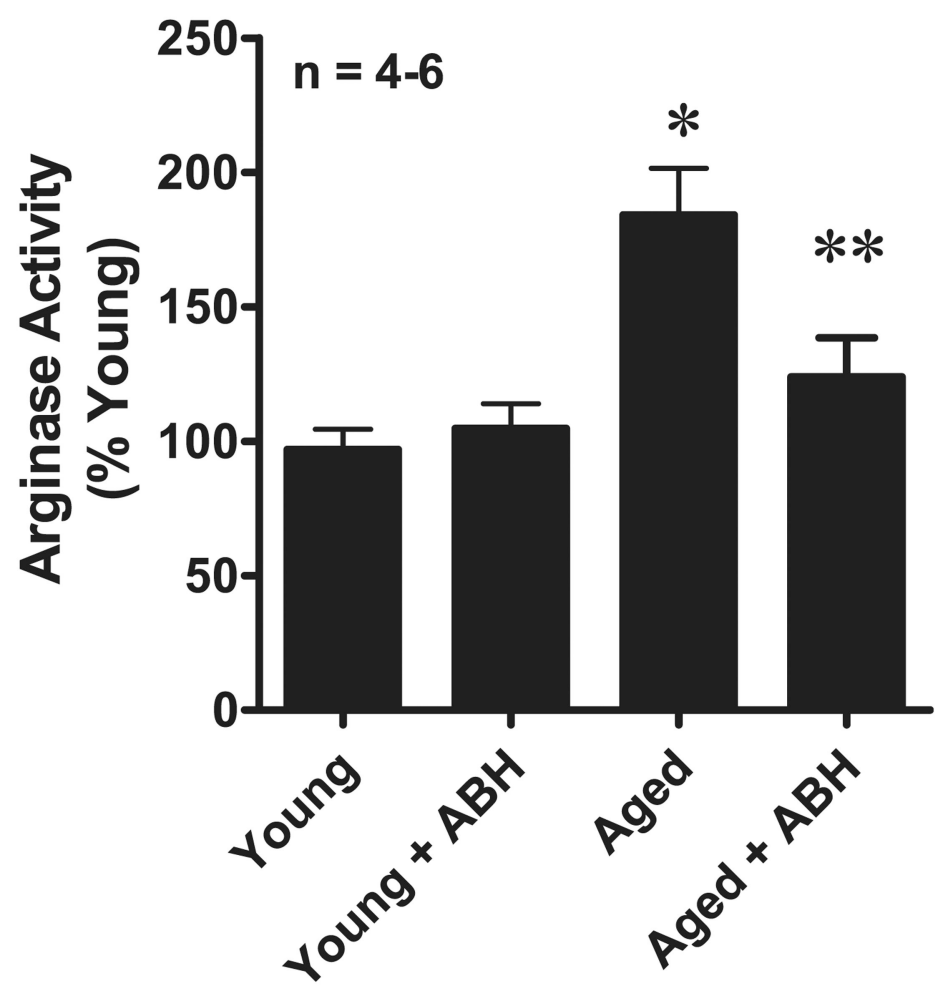

Figure 4.

Total arginase activity in young and aged rat penes with and without treatment with the arginase inhibitor 2-(S)-amino-6-boronohexanoic acid $(\mathrm{ABH}) . \mathrm{n}$ indicates number of tissue samples; * $P<.05$ compared with young and young $+\mathrm{ABH} ; * *, P<.05$ compared with aged. 